\title{
Pathology of carbon monoxide poisoning in two cats
}

\author{
Arya Sobhakumari ${ }^{1}$, Robert H. Poppenga ${ }^{1}$, J. Brad Pesavento ${ }^{1}$ and Francisco A. Uzal ${ }^{2^{*}}$ (D)
}

\begin{abstract}
Background: Carbon monoxide (CO), a common cause of poisoning in human beings has also been implicated in the death of animals. Though there are multiple studies on $\mathrm{CO}$ poisoning and relevant lethal blood $\mathrm{COHb}$ concentrations in humans, there are no reliable reports of diagnostic lethal carboxyhemoglobin percentage of saturation (COHb\%) in cats. Additionally, due to shared housing environments, exposures to companion animals can be a surrogate for lethal exposures in human beings and provide valuable information in concurrent forensic investigations.

Case presentation: Two adult Singapura brown ticked cats were submitted to the California Animal Health and Food Safety Laboratory (CAHFS) for necropsy and diagnostic work-up. These animals were found dead along with their two deceased owners. Similar lesions were observed in both cats. At necropsy, gross lesions consisted of multifocal, large, irregular, bright red spots on the skin of the abdomen and the inner surface of ear pinnae, bright red muscles and blood. The carcasses, and tissues fixed in formalin retained the bright red discoloration for up to two weeks. Microscopic lesions included diffuse pulmonary congestion and edema, and multifocal intense basophilia of cardiomyocytes mostly affecting whole fibers or occasionally a portion of the fiber. Based on the clinical history,gross and microscopic changes, cyanide or carbon monoxide poisoning was suspected. Blood samples analyzed for carbon monoxide showed 57 and $41 \%$ carboxyhemoglobin $\mathrm{COHb} \%$. Muscle samples were negative for cyanide.

Conclusion: There are no established reference values for lethal $\mathrm{COHb}$ concentration in cats. The $\mathrm{COHb} \%$ values detected in this case which fell within the lethal range reported for other species, along with the gross lesions and unique histological findings in the heart suggest a helpful criteria for diagnosis of CO intoxication associated death in cats. This case demonstrates that since pets share the same environment as human beings and often are a part of their activities, they can be useful adjuncts in potential forensic investigations to help solve human cases.
\end{abstract}

Keywords: Carbon monoxide, Cats, COHb \%, Forensic investigation

\section{Background}

Carbon monoxide $(\mathrm{CO})$ poisoning has been frequently described in human beings. However, information about $\mathrm{CO}$ poisoning and associated lesions in animals is scant to non-existent, especially in cats. In particular, there are no reports of diagnostic lethal carboxyhemoglobin percentage of saturation $(\mathrm{COHb} \%)$ in cats and the threshold for toxicity in this species has not been established. It is possible that animal cases remain undiagnosed due to lack of adequate testing opportunities in veterinary diagnostic laboratories. The main reason for $\mathrm{CO}$ poisoning

\footnotetext{
* Correspondence: fuzal@cahfs.ucdavis.edu

${ }^{2}$ California Animal Health and Food Safety Laboratory System, San

Bernardino branch, School of Veterinary Medicine, University of California

Davis, 105 W Central Ave, San Bernardino, CA 92408, USA

Full list of author information is available at the end of the article
}

in human beings is incomplete combustion of hydrocarbons in non-ventilated buildings, associated with faulty furnaces and house fires. This seems to be the same mechanism for $\mathrm{CO}$ poisoning in companion animals such as dogs and cats, because of their shared environment with humans.

$\mathrm{CO}$ has more than 210 times greater affinity for hemoglobin than oxygen $\left(\mathrm{O}_{2}\right)$ [1], readily forming carboxyhemoglobin $(\mathrm{COHb})$, thus reducing the oxygen carrying capacity of red blood cells and leading to hypoxemia and tissue hypoxia. Formation of $\mathrm{COHb}$ not only displaces oxygen but $\mathrm{CO}$ causes a conformational change in hemoglobin after the binding, resulting in greater affinity for oxygen in the remaining heme moieties. This leads to a shift to left of the $\mathrm{O}_{2}$ dissociation curve and reduced delivery of $\mathrm{O}_{2}$ to tissues $[2,3]$. $\mathrm{CO}$ 
has high affinity for myoglobin and binding to cardiac myoglobin can cause myocardial depression, hypotension and arrhythmias. Cardiac decompensation results in further tissue hypoxia which is the ultimate cause of death [4].

Current scientific literature on spontaneous CO intoxication in small animals is limited. While a few papers have been published describing spontaneous $\mathrm{CO}$ intoxication in dogs $[3,5,6]$, there are no reports that covered gross and histological lesions in various organs in cats. There is only one report on respiratory distress upon CO poisoning in cats, although pathology of the intoxication was not described in that report [7].

This case describes for the first time in detail the gross, microscopic and toxicological findings, specifically the lethal blood $\mathrm{COHb}$ concentration, in two cats that died following $\mathrm{CO}$ intoxication. This report also indicates the utility of postmortem blood as a feasible sample for diagnostic confirmation. Additionally, it emphasizes the significance of testing animals as a useful adjunct to concurrent human forensic investigations since pets share the same environment as owners and face similar risks with respect to exposure to various chemicals, including $\mathrm{CO}$.

\section{Case presentation}

Two adult Singapura brown ticked cats (a spayed female and a neutered male) were submitted to the San Bernardino branch of CAHFS for necropsy and diagnostic work up. The cats had been found dead in a household together with their two deceased owners. The exact date of death was unknown.

Grossly, both cat carcasses were in good nutritional condition and moderate state of postmortem decomposition. The stomach of cat A was almost empty except for $\sim 2$ mls of mucous fluid and the stomach of cat B had a $\sim 50 \mathrm{mls}$ of semi digested kibble. Both cats presented the following gross abnormalities: bright pink-red discoloration of the aqueous fluid (this change was most marked in Cat A), multifocally bright red discoloration on the skin of the abdomen (Fig. 1) and inner surface of the ear pinnae (Fig. 2), bright red skeletal muscles, congestion and bright red discoloration of the abdominal serosa, congested and edematous lungs, mild hydrothorax and hydropericardium. No other significant gross abnormalities were observed in either carcasses. In particular, no gross abnormalities were observed in the brain of either cat.

After necropsy, the carcasses were stored refrigerated for two weeks before they were submitted for cremation, and they retained the bright red discoloration for the whole period (Fig. 3). Formalin fixed tissues and the formalin in which tissues were immersed, retained similar discoloration for the first two weeks after collection; this discoloration faded progressively after that.

Tissue samples from most organs of both cats, including representative areas of the brain (cortex, corpus striatum, thalamus, midbrain, cerebellum and medulla), were routinely

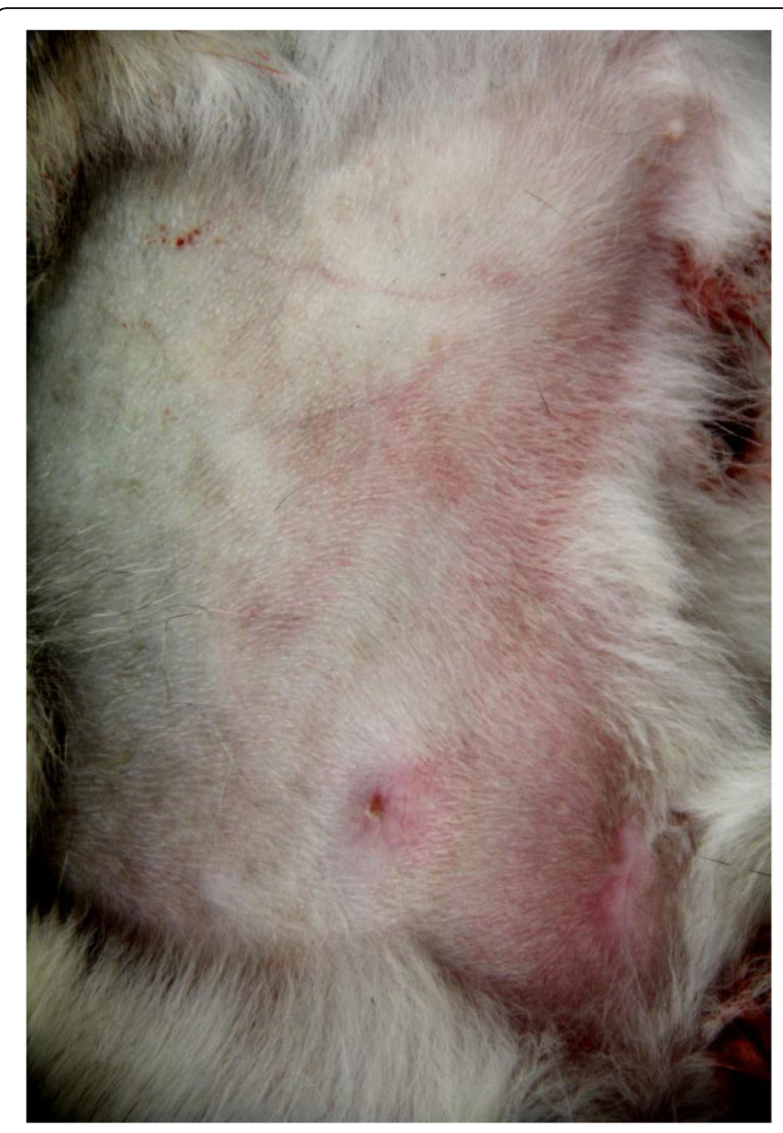

Fig. 1 Gross findings in a cat with carbon monoxide intoxication. Bright red discoloration on the skin of the abdomen

processed for the production of HE stained sections. Selected sections of heart from both animals were also stained with Von Kossa to investigate possible calcium deposits and Phosphotungstic acid hematoxylin (PTHA) to highlight the structure of myocardiocytes.

Microscopic lesions were similar in both cats and included diffuse pulmonary congestion, interstitial and alveolar edema, and multifocal intense basophilia of cardiomyocytes (Fig. 4). The latter mostly affected whole fibers but occasionally only a portion of the fiber, with a clear transverse line of demarcation from the rest of the fiber. Rarely, discrete areas of hypercontraction bands were seen in individual cardiomyocytes; these lesions were visible on $\mathrm{HE}$ sections but were highlighted on PTHH stained sections. Examination of Von Kossa stained sections of the heart was unremarkable. No other significant microscopic abnormalities were observed in any of these cats. Transmission electron microscopy of formalin fixed heart from both cats was performed but was unrewarding.

Based on the clinical history, gross and microscopic changes, cyanide or carbon monoxide poisoning was suspected. Skeletal muscle from both cats was analyzed 


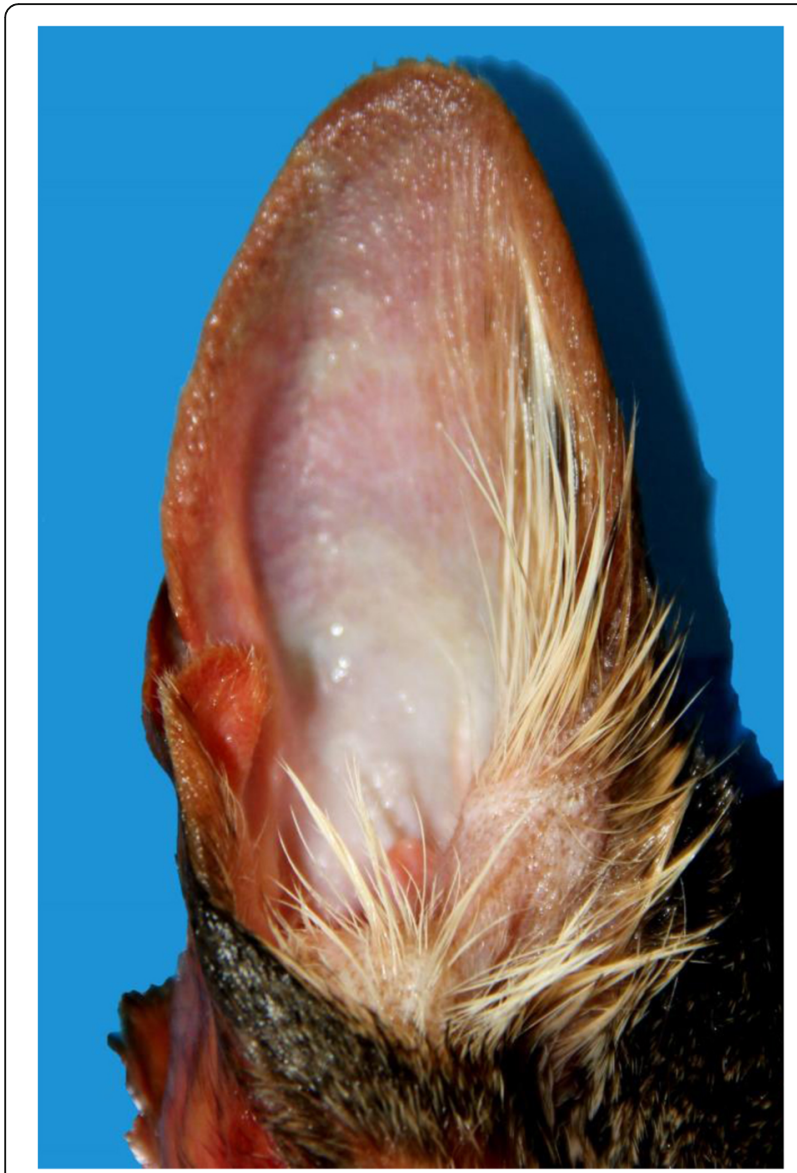

Fig. 2 Gross findings in a cat with carbon monoxide intoxication. Bright red discoloration on the inner surface of the ear pinna

for cyanide by a distillation method as previously described [8]. Briefly, cyanide in the tissues was converted to hydrogen cyanide gas which was chlorinated and converted to a colored dye. The absorbance was then measured spectrophotometrically at $578 \mathrm{~nm}$ and cyanide quantitated from a standard curve. Cyanide was not detected in the muscle of either cat at or above a reporting limit of 1 ppm.

Since the cyanide test was negative, postmortem blood samples were analyzed for $\mathrm{CO}$ by a modification of the Comopac $^{\ominus}$ electrochemical gas meter as previously described [9]. Briefly, blood was mixed with saturated sodium chloride in a screw top glass vial adapted to fit onto a Genesis ${ }^{\oplus}$ portable CO monitor (Thermo Scientific) and $\mathrm{CO}$, liberated in a closed headspace, was measured for $5 \mathrm{~min}$. The $\mathrm{Hb}$ was measured by an azidemethemoglobin method using HemoCue ${ }^{\circledast}$ Hb 201 System. The blood $\mathrm{COHb}$ was reported as $\%$ saturation of $\mathrm{Hb}$ with $\mathrm{CO}$. $\mathrm{COHb}$ saturation was $57 \%$ and $41 \%$ for cats $\mathrm{A}$ and $\mathrm{B}$, respectively.

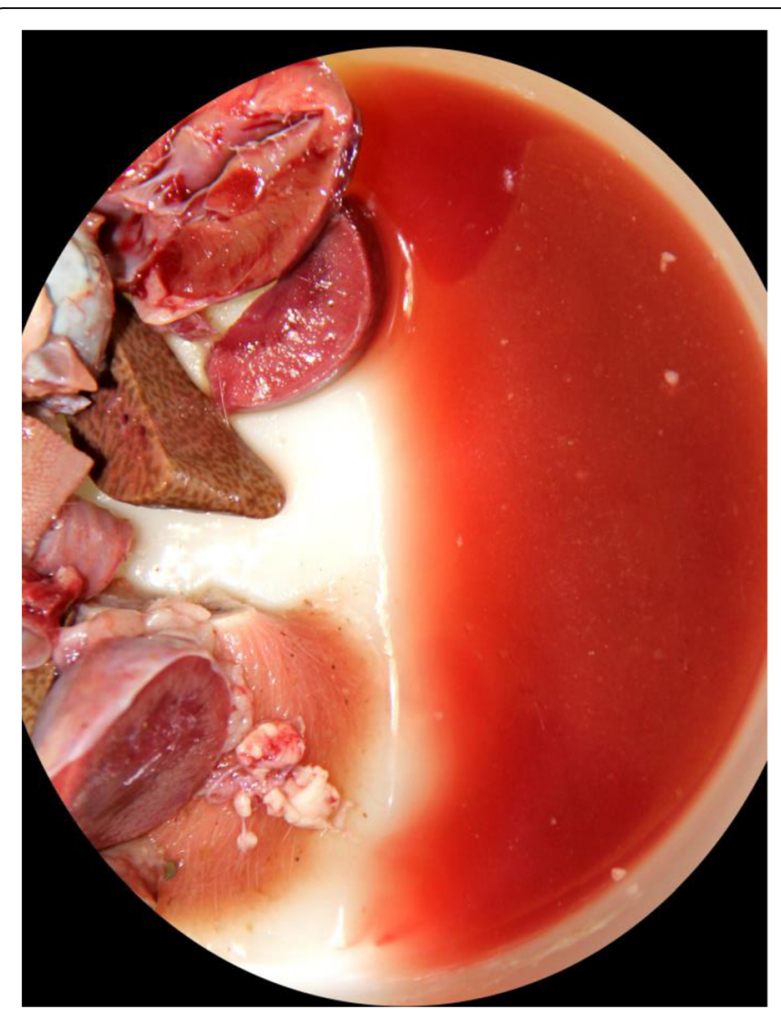

Fig. 3 Gross findings in a cat with carbon monoxide intoxication. Bright red discolored formalin where tissues were immersed for 2 weeks

\section{Discussion and conclusions}

In this case, a presumptive diagnosis of $\mathrm{CO}$ intoxication was established based on the clinical history, gross and microscopic findings. Gross and microscopic changes have not been described before in cats intoxicated with carbon dioxide. In humans and other animals intoxicated with $\mathrm{CO}$ bright red discoloration of skin, mucosas and muscle, cherry red color of the blood and brain changes related to anoxia, including necrosis in the cortex and white matter of cerebral hemispheres, globus pallidus and brainstem have been described and are suggestive, but non-specific for this intoxication $[3,5,6]$. These changes are not, however, considered pathognomonic and confirmation of the diagnosis should be based on detection of toxic levels of $\mathrm{COHb}$ in the blood of cadavers, which is standard practice in human forensic medicine.

In this case, both cats had gross findings considered compatible with carbon monoxide intoxication in humans and dogs $[3,5,6]$. In addition, bot animals had blood values of $\mathrm{COHb}$ which are considered toxic for humans and, in absence of reference values for cats, this finding was used to confirm the diagnosis of $\mathrm{CO}$ intoxication. 


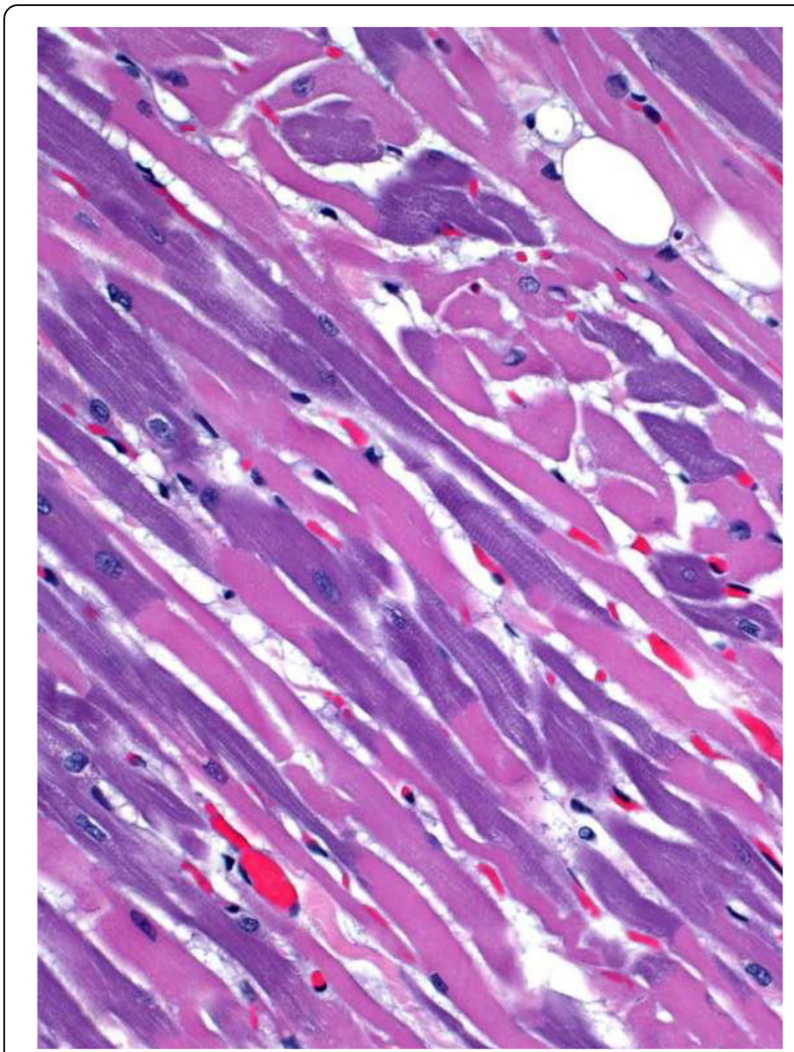

Fig. 4 Microscopic findings in a cat with carbon monoxide intoxication. Multifocal basophilia in cardyomyocytes. HE, 250X

Brain changes have been described in human beings and dogs intoxicated with carbon monoxide before. In the cats presented here, no gross or microscopic lesions were observed in the brain. This might be related to a very acute clinical course with no time for central nervous system lesion development. This is, however, only speculation, as clinical information was not available on these cats which were found dead.

The microscopic discoloration of cardiomyocytes of these two cats is an unusual lesion that has not been described before in humans or animals intoxicated with $\mathrm{CO}$. Because no ultrastructural lesions were observed in the heart of either cat, the pathogenesis of this discoloration could not be determined; it is possible that biochemical alterations not accompanied by morphological (microscopic or ultrastructural) changes occurred associated with $\mathrm{CO}$ intoxication.

$\mathrm{CO}$ is a colorless, odorless, non-irritant gas produced by incomplete combustion of fuels and is a leading cause of human poisoning and mortality in the US [10]. Two mechanisms of action (acute and delayed) exist for $\mathrm{CO}$ intoxication. The formation of $\mathrm{COHb}$ in intoxicated individuals decreases the oxygen carrying capacity of hemoglobin and shifts the $\mathrm{O}_{2}$ dissociation curve to the left impairing $\mathrm{O}_{2}$ release resulting in tissue hypoxia, which is mainly responsible for the clinical signs of $\mathrm{CO}$ poisoning. However, it has been suggested that the above mechanism alone does not account for the toxicity of $\mathrm{CO}$ since in many instances the concentration of $\mathrm{COHb}$ does not correlate with the clinical signs. In an early study, when dogs were exposed to $13 \%$ CO in atmospheric air, the animals died within one hour and had $\mathrm{COHb}$ concentrations of 54-90\% [5]. However, the transfusion of $80 \% \mathrm{COHb}$ saturated blood to healthy recipient dogs which resulted in a similar $57-64 \% \mathrm{COHb}$ in their blood did not cause intoxication $[5,11]$. It is suggested that acute toxicity of $\mathrm{CO}$ may be the result of binding of $\mathrm{CO}$ to heme proteins other than hemoglobin such as cytochromes and myoglobin, which interferes with cellular respiration and generation of free radicals through disruption of oxidative metabolism [12, 13]. Additionally, $\mathrm{CO}$ has been found to stimulate guanylyl cyclase resulting in relaxation of vascular smooth muscles, cerebral vasodilation and loss of consciousness $[6,14]$. $\mathrm{CO}$ also displaces nitric oxide $(\mathrm{NO})$ from platelets leading to peroxynitrite formation, endothelial damage, leukocyte adhesion, formation of free radicals, and lipid peroxidation in the brain microvasculature which may be a mechanism for delayed neurological sequelae [15].

Levels of $\mathrm{COHb}$ have been measured in many species both at baseline and associated with lethality. In human beings, clinical signs of $\mathrm{CO}$ toxicity start at $20 \% \mathrm{COHb}$ and death occurs between 50 and $80 \% \mathrm{COHb}$ [16]. In dogs mortality was reported to occur within one hour when exposed to $13 \% \mathrm{CO}$ in atmospheric air with subsequent $\mathrm{COHb}$ concentrations of 54-90\% [5]. Ashbaugh measured $\mathrm{COHb}$ in healthy, clinically normal dogs and fire victim dogs, and found that the values ranged between $5.6-6.4 \%$ and $8.3-37 \%$, respectively [17]. $\mathrm{COHb}$ concentration has been reported in two cats that became ataxic and tachypneic following exposure to generator fumes in a closed warehouse for $8 \mathrm{~h}$ [7]. These animals had $\mathrm{COHb}$ concentrations of 5 and $9 \%$ which declined to baselines levels of $0-4 \%$ after oxygen therapy and supportive treatment. However, there are no guidelines to interpret lethal $\mathrm{COHb}$ concentrations in blood of cats intoxicated with $\mathrm{CO}$. In the present case, the concentration of $\mathrm{COHb}$ in both the cats fell within the lethal ranges reported for dogs and humans. Since no previous data was available to compare, we concluded that the detected concentrations are lethal for cats in the context of the characteristic lesions.

Although measurement of blood $\mathrm{COHb}$ is used as a diagnostic tool for $\mathrm{CO}$ poisoning, it may not fully correlate with the severity of the symptoms. The $\mathrm{COHb}$ in blood is not an absolute index of compromised oxygen delivery at the tissue level. Additionally, unmeasured $\mathrm{CO}$ 
uptake in tissues, which is hypothesized to increase during hypoxia because of the competition of $\mathrm{CO}$ and $\mathrm{O} 2$ on the binding site of hemoproteins also contributes to the clinical signs. Therefore, the limitation of $\mathrm{COHb}$ levels is that it can be used to guide therapeutic strategies but not predict treatment outcomes $[7,18]$.

The incidence of $\mathrm{CO}$ intoxication in pets is unknown. The Pet Poison Helpline (St. Paul, Minnesota) receives an average of $3-4$ suspected or confirmed cases of $\mathrm{CO}$ poisoning every year, with a potential for many suspicious cases unconfirmed due to lack of adequate diagnostic facilities.

Because of the proximity of pets to human beings, investigation of morbidity or mortality can be valuable in concurrent human forensic investigations. The use of dog and cat hair DNA, tissues, saliva and pet food remnants have become more common in criminal investigations helping solve numerous cases $[19,20]$. An unusual case of apparent suicide/homicide involving two human beings and a dog was described where the cause of death was identified to be diazepam overdose which was later detected in the liver tissue and dog food remnants [21]. In the present case, the presumed sudden death of both human beings and the cats in the same environment bolsters the argument that a multidisciplinary approach involving pets would be more likely to yield successful investigational outcomes since both species were likely exposed to the same toxicant.

\section{Abbreviations \\ CAHFS: California Animal Health and Food Safety Laboratory; CO: Carbon monoxide; $\mathrm{COHb}$ : Carboxyhemoglobin; $\mathrm{COHb} \%$ : Carboxyhemoglobin percentage of saturation; $\mathrm{HB}$ : Hemoglobin; mls: Milliliters; $\mathrm{O}_{2}$ : Oxygen; ppm: Parts per million; PTAH: Phosphotungstic acid hematoxylin}

\section{Acknowledgements}

The authors thank Sabine Hargrave and Bill Torres for the chemical analysis.

\section{Funding}

CAHFS provided financial support for publication of this article.

Availability of data and materials

Data and materials are presented in the main document.

\section{Authors' contributions}

FAU performed necropsy, described the histopathological findings, wrote part of the manuscript and edited several versions of it including the final version. JBP performed the electron microscopy. AS facilitated the toxicology analysis, interpreted the results and wrote the manuscript. RHP provided helpful discussions, critically reviewed the manuscript and added final corrections. All authors approved the final manuscript.

\section{Ethics approval}

Post-mortem samples were collected in accordance with institutional guidelines. The two cats included in this study were submitted to our laboratory (the California Animal health and Food Safety Lab -CAHFS-) by the legal owner of these animals, a state government agency for necropsy and diagnostic work up to establish cause of death. Per UCDavis and CAHFS regulations, neither ethics approval nor consent to use diagnostic material submitted to our lab for publication is required. The submitter signed the following statement in the submission form which accompanied the bodies of these two cats: "I understand that specimens submitted are the property of CAHFS".

\section{Consent for publication}

Not applicable. Please see above.

\section{Competing interests}

The authors declare that they have no competing interests.

\section{Publisher's Note}

Springer Nature remains neutral with regard to jurisdictional claims in published maps and institutional affiliations.

\section{Author details}

'California Animal Health and Food Safety Laboratory System, Davis branch, School of Veterinary Medicine, University of California Davis, Davis, USA. ${ }^{2}$ California Animal Health and Food Safety Laboratory System, San Bernardino branch, School of Veterinary Medicine, University of California Davis, 105 W Central Ave, San Bernardino, CA 92408, USA.

Received: 21 November 2017 Accepted: 20 February 2018

Published online: 05 March 2018

\section{References}

1. Rodkey FL, O'Neal JD, Collison HA, Uddin DE. Relative affinity of hemoglobin $\mathrm{S}$ and hemoglobin a for carbon monoxide and oxygen. Clin Chem. 1974;20:83-4.

2. Roughton F, Darling F. The effect of carbon monoxide on oxy-hemoglobin dissociation curve. Am J Phys. 1944:141:17-31.

3. Kent M, Creevy KE, Delahunta A. Clinical and neuropathological findings of acute carbon monoxide toxicity in chihuahuas following smoke inhalation. Am Anim Hosp Assoc. 2010;46:259-64.

4. Blumenthal I. Carbon monoxide poisoning. J R Soc Med. 2001:94:270-2

5. Varma D, Chemtob S. Carbonmonoxide: from public health risk to painless killer. In: Gupta RC, editor. Handbook of toxicology of chemical warfare agents. Amsterdam: Academic Press; 2009. p. 267-81.

6. Ashbaugh EA, Mazzaferro EM, McKierman BC, Drobatz KJ. The association of physical examination abnormalities and carboxyhemoglobin concentrations in 21 dogs trapped in a kennel fire. J Vet Emerg Crit Care (San Antonio). 2012:22:361-7.

7. Berent A, Todd J, Sergeeff J, Powell LL. Carbon monoxide toxicity: a case series. J Vet Emerg Crit Care. 2005;15:128-35.

8. APHA. Method 4500-CN. In: Standard methods for examination of water and waste water: American Public Health Association; 1985. https://archive. org/stream/gov.law.apha.method.4500-cn.1992/apha.method.4500-cn.1992_ djvu.txt. Accessed 20 Oct 2017

9. Bogusz $\mathrm{M}$, Aderjan $\mathrm{R}$, Bosche J. The determination of carbon monoxide in blood by means of electrochemical pocket gas meter. J Anal Toxicol. 1988; 12:225-8

10. American Association of Poison Control Centers provides safety recommendations to avoid poison hazards this holiday season. In: American association of poison control Centres. Alexandria, Virginia; 2016. http://www. aapcc.org/press/52/. Accessed 20 Oct 2017.

11. Goldbaum LR, Ramirez RG, Absalon KB. What is the mechanism of carbon monoxide toxicity? Aviat Space Environ Med. 1975:46:1289-91.

12. Ball EG, Strittmatter CF, Cooper O. The reaction of cytochrome oxidase with carbon monoxide. J Biol Chem. 1951:193:635-47.

13. Cooper CE, Brown GC. The inhibition of mitochondrial cytochrome oxidase by the gases carbon monoxide, nitric oxide, hydrogen cyanide and hydrogen sulfide: chemical mechanism and physiological significance. J Bioenerg Biomembr. 2008;40:533-9.

14. Verma A, Hirsch DJ, Glatt CE, Ronnett GV, Snyder SH. Carbon monoxide: a putative neural messenger. Science. 1993;259:381-4.

15. Utz J, Ullrich V. Carbon monoxide relaxes ileal smooth muscle through activation of guanylate cyclase. Biochem Pharmacol. 1991;41:1195-201.

16. Thom SR. Carbon monoxide-mediated brain lipid peroxidation in the rat. Appl Physiol. 1990;68:997-1003.

17. Ryter SW, Otterbein LW. Carbon monoxide in biology and medicine. BioEssays. 2004;26:270-80. 
18. Abelsohn A, Sanborn MD, Jessiman BJ, Weir E. Identifying and managing adverse environmental health effects: carbon monoxide poisoning. CMAJ. 2002;166:1685-90.

19. Menotti-Raymond MA, David VA, O'Brien OJ. Pet cat hair implicates murder suspect. Nature. 1997;386:774.

20. Halverson J. Pet forensics. In: Joy of DNA Sherlock's DNA case files. http:// joyofdna.com/dr-joys-story-2/. Accessed 21 Oct 2017.

21. Harding BE, Sullivan LM, Adams S, Middleberg RA, Wolf BC. Multidisciplinary investigation of an unusual apparent homicide/suicide. Am J Forensic Med Pathol. 2011;32:208-12.

Submit your next manuscript to BioMed Central and we will help you at every step:

- We accept pre-submission inquiries

- Our selector tool helps you to find the most relevant journal

- We provide round the clock customer support

- Convenient online submission

- Thorough peer review

- Inclusion in PubMed and all major indexing services

- Maximum visibility for your research

Submit your manuscript at www.biomedcentral.com/submit
Biomed Central 